\title{
Scenario Simulation of the Influence of Land Use Change on the Regional Temperature in a Rapidly Urbanizing Region: A Case Study in Southern-Jiangsu, China
}

\author{
Xinli Ke, ${ }^{1}$ Enjun $\mathrm{Ma}^{2}{ }^{2}$ and Yongwei Yuan ${ }^{3}$ \\ ${ }^{1}$ College of Land Management, Huazhong Agricultural University, Wuhan 430079, China \\ ${ }^{2}$ School of Mathematics and Physics, China University of Geosciences (Wuhan), Wuhan 430074, China \\ ${ }^{3}$ Faculty of Resources and Environmental Science, Hubei University, Wuhan 430062, China \\ Correspondence should be addressed to Xinli Ke; kexl@igsnrr.ac.cn
}

Received 29 August 2013; Accepted 4 December 2013; Published 16 February 2014

Academic Editor: Burak Güneralp

Copyright ( 2014 Xinli Ke et al. This is an open access article distributed under the Creative Commons Attribution License, which permits unrestricted use, distribution, and reproduction in any medium, provided the original work is properly cited.

\begin{abstract}
It has been shown that land use change in urbanized region, especially urban land expansion, will influence regional climate. However, there has been very little research on the climate effects of the future land use change in a rapidly urbanizing region. Taking the southern part of Jiangsu province in China as the study area and through a scenario analysis, the influence of land use change on the regional temperature was analyzed from the perspective of land surface radiation budget and energy balance. The results indicated that (1) the monthly average temperature is significantly higher under the Rapid Economic Growth (REG) scenario than under the Cooperate Environmental Sustainability (CES) scenario in 2050, especially in the hottest month (July). (2) The range of high-temperature regions is much wider under the REG scenario than it is under the CES scenario in 2050. (3) The land surface net radiation and latent heat flux are two key factors through which land use change influences the regional temperature in the study area, and the latent heat flux plays a dominant role. (4) Land use change mainly influences the land surface net radiation by altering the land surface albedo and emissivity. These results are helpful to mitigate regional climate change effects caused by land use change.
\end{abstract}

\section{Introduction}

Urbanization is one of the most dramatic changes in the world. Urban land expansion is a prominent feature of urbanization. With the rapid development of urbanization, the land surface is replaced by the impermeable ground such as cement, asphalt, which has made urban environmental problems become increasingly serious $[1,2]$. Among them, the increasing urban heat island effect has become the typical problem of the urban environmental change and has endangered the daily life and safety of the urban residents $[3,4]$. Urbanization as a typical performance of human land use activities can affect local and regional climate change, and even large-scale atmospheric circulation [5]. Underlying surface change would cause the redistribution of Earth surface's heat and moisture in the process of urbanization, causing changes in local and even regional climate $[6,7]$.
Research on the impacts of urbanization on climate mainly focuses on urban heat island and urban rain island. Since the urban heat island was proposed in 1833, it has been verified that urban heat island exists in many cities of different types and sizes $[8,9]$. A large number of studies suggest that the urban heat island intensity exhibits different characteristics along with the location and the type of the city, the conditions of periurban area and so on [10, 11]. Globalscale studies suggest that urbanization plays an important role in raising global surface temperature in recent years $[12,13]$. However, almost all the studies have confirmed that the urbanization, especially urban land expansion will lead to the rising surface temperature. Urbanization changes the underlying surface and makes the urban areas temperature rise. Precipitation is another important aspect of the impact of urbanization on regional climate. In the process of urbanization, natural vegetation is replaced by asphalt, 
buildings, and other artificial land surfaces, which results in changes on the surface roughness, albedo and soil moisture, and other surface properties, and affects regional precipitation through their impacts on the radiation balance, water balance, and other processes. Early studies showed that in rapid urban development period, there will be unusually high precipitation in urban areas [14], and the areas which are close to the metropolitan areas are more prone to have heavy rains [15-17]. With the growth of the urban population, raining in the afternoon seems to increase in large cities [14]. Another study showed that the increasing intensity of showers in monsoon season in the urban areas may be relevant to heat island [18]. Further studies showed that effects of urbanization on precipitation intensity showed different laws in different terrains and climatic backgrounds [19]. In addition, the impact of urbanization on precipitation is not limited to urban areas but also to urban downwind areas $[20,21]$.

As to research methods, research on impacts of urbanization on climate change is mainly based on studies of observational data and numerical simulation. Early researches about impacts of urbanization on climate change mainly rely on observation site data, combined with demographic data or land use data, using empirical orthogonal function [22], principal component analysis $[23,24]$, and other methods to select reference stations and urban stations. Through comparative analysis of observational data discrepancies between reference stations and urban stations, the impacts of urbanization on climate change can be assessed. This method is simple, intuitive, and persuasive, but it is affected by the site classification results and the number of samples. To solve this problem, Kalnay and Cai (2003) [25], based on the characteristics of NCEP/NCAR reanalysis data which did not use ground-based observations information in the assimilation process, proposed an idea which could reflect impacts of urbanization on the regional climate change according to comparative observations and reanalysis differences [25]. Although this approach has achieved good results [26], its reliability has been disputed $[27,28]$. In recent years, with the development of remote sensing technology, the research of the impacts of urbanization on regional climate change has made a great progress by using remote sensing technology to extract information on land use changes and land surface air temperature and precipitation data [29-31]. These methods provided a good support to describe the impacts of urbanization on climate change. However, these methods are inadequate to analyze the impact mechanism of urbanization on climate. Therefore, it is necessary to introduce numerical simulation in researching the key processes that urbanization affects regional climate change from the perspective of the mechanism. Sensitivity experiments of two-dimensional scale model showed that sensible heat fluxes caused by urban surface changes played a key role in climate change, and roughness changes affected the spatial heterogeneity of climate change [32]. Sensitivity test of RAMS/TEM coupled model indicated that urban heat island plays a key role in inducing downwind convective systems [33]. Sensitivity test of WRF/NOAH coupled model indicated that urbanization mainly through two aspects of increasing heat sense and reducing moisture together affected convective activity thus realizing regional climate change [34]. It can clearly be seen that numerical simulation method provides support for the in-depth understanding of the process: urbanization, land surface change, key biogeophysical parameters change, and climate change.

This paper took Southern-Jiangsu in China as the case study area. Firstly, DLS (Dynamics of Land System) model is employed to simulate future land use change in study area at various scenarios. Then the simulation results of land use change were processed so as to satisfy the requirements of underlying surface data for WRF (Weather Research and Forecast) model. On this basis, the WRF model was used to simulate the impacts of future land use change on regional climate change, to scientifically understand the key parameters and the key process of the impacts of region's future land use change on regional climate change, and to provide scientific basis for the rational regional land use planning to mitigate climate change.

\section{Study Area}

China is the largest developing country in the world, experiencing rapid urbanization. Yangtze River Delta is one of the most rapidly urbanizing regions in China, and land use change caused by urban expansion is very intense in this area. Studies have shown that the urbanization of Yangtze River Delta region has obvious effects on its climate. SouthernJiangsu is an important part of the Yangtze River Delta, the impact of regional urban land expansion on climate change has also been widely concerned [35]. However, current researches mainly focus on land use change and climate change, revealing the impacts of urbanization on regional climate change. Few studies focus on the impacts of future urban land use change on regional climate change. The scientific understanding of the impacts of future land use change on the regional climate change is the basis of a scientific and rational land use planning to mitigate regional climate change. Therefore, there is an urgent need to reveal the impacts of future land use changes of typical urbanized areas on regional climate change.

Southern-Jiangsu is located in the Yangtze River Basin in China, with superior geographical environment, pleasant climate and convenient irrigation, vast plains, and fertile soil. There are five cities in Southern-Jiangsu, including Nanjing, Zhenjiang, Changzhou, Wuxi, and Suzhou (Figure 1). In history, Southern-Jiangsu was China's most prosperous place because agriculture there was well developed. SouthernJiangsu is closed to Shanghai and it is a large hinterland of Shanghai, so it has geographical advantages. Because of its proximity to Shanghai, Southern-Jiangsu developed strong economic ties with Shanghai.

Southern-Jiangsu is one of the most populous and urbanized and the fastest growing economic regions in China. With Shanghai's role in driving the economic development, Southern-Jiangsu grows rapidly in economic development and urbanization. In 2008, the regional GDP of SouthernJiangsu was 1.85 trillion Yuan, accounting for $6.4 \%$ of the 


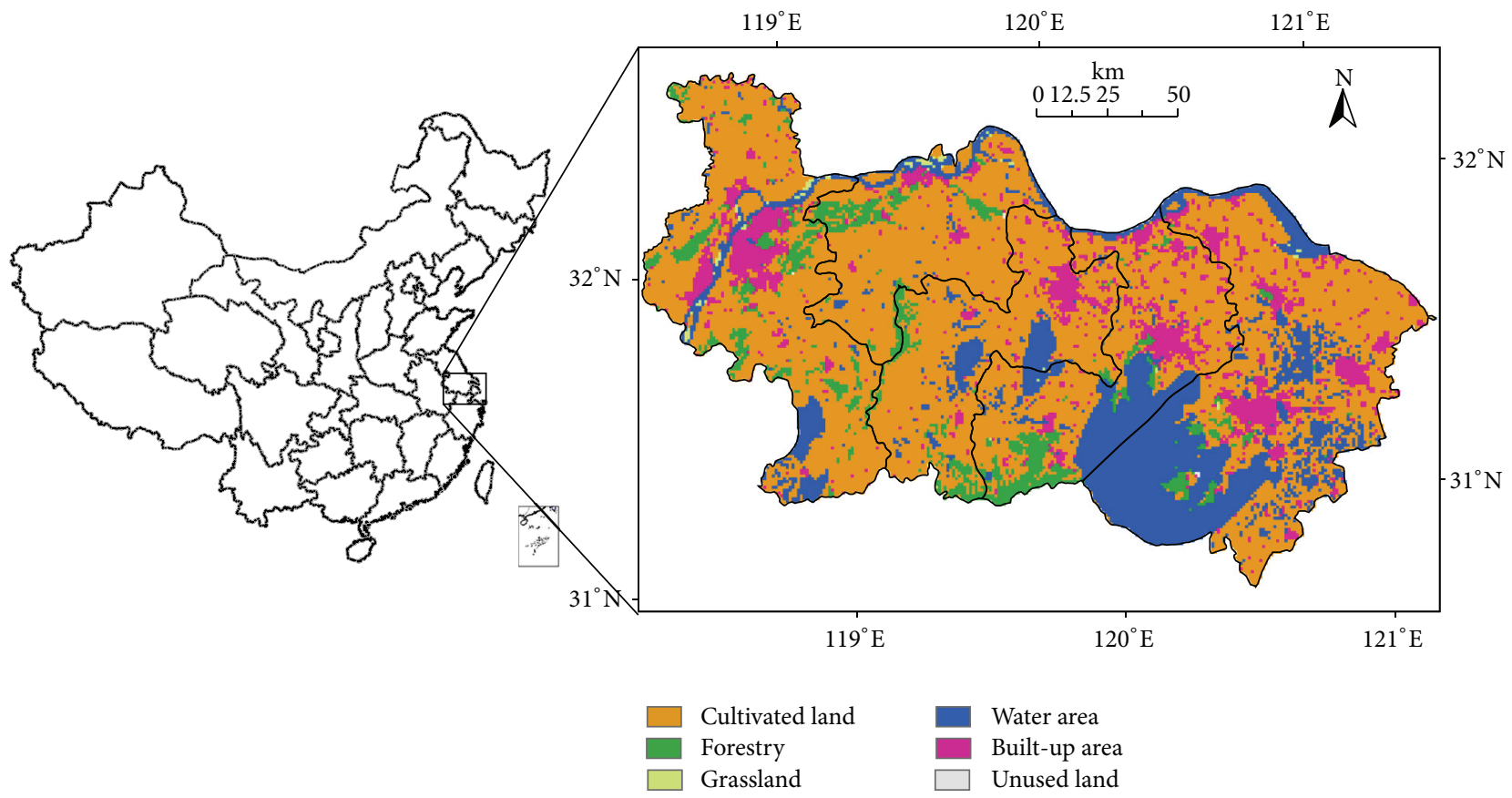

Figure 1: Location of Southern-Jiangsu.

whole country. Southern-Jiangsu is also relatively dense with cities and towns, and urbanization level is high. In 2008, Southern-Jiangsu's urbanization rate reached $67.7 \%$, and per capita GDP reached 61,823 Yuan reaching the level of moderately developed countries.

\section{Data and Methodology}

3.1. Data Sources. The data includes the land use data, socioeconomic data, and data of natural environmental conditions of Southern-Jiangsu.

Land use data is mainly used for scenario simulations of land use change. In this study, land use data of SouthernJiangsu in 2000 and 2008 are obtained through remote sensing images interpretation. These land use data are composed of six land types, including farmland, forestry land, grassland, built-up land, water bodies, and unused land. Among them, land use data in 2000 came from the Land Use Database of Data Center Resources and Environment, Chinese Academy of Science [36]. The database consists of Landsat TM/ETM+ image interpretation with a spatial resolution of $30 \times 30 \mathrm{~m}$. Land use data in 2008 is interpreted by Landsat ETM+ images.

The natural environmental conditions data included DEM data of the study area, the distance from the city at all levels, the distance from the railways, the distance from the roads, and the distance from the rivers. DEM data came from the data of Shuttle Radar Topography Mission (SRTM) of NASA. This paper hierarchically calculated the distance from the city at all levels to each $100 \times 100 \mathrm{~m}$ grid, using the Landsat TM/ETM+ geometric correction in 2000 that covered Southern-Jiangsu to outline the major river systems and the network of transport of the study area and to work out the distance from each $100 \mathrm{~m} \times 100 \mathrm{~m}$ grid to railways, roads, and rivers.

The social and economic statistical data included the population of Southern-Jiangsu, per capita retail sales of social consumer goods, the total investment in fixed assets, per capita fiscal revenue, the gross output of the second industry, and grain yield per unit area from 2000 to 2008. The above data come from Jiangsu Statistical Yearbook.

3.2. DLS Model. DLS is a land use dynamic simulation model based land use change mechanism, which in accordance with the driving forces analysis of land use change, scenario forecasting, and supply industrial allocation of land area and space allocation carrying out dynamic simulations of land use change from region and grid (Figure 2). DLS model consists of four modules, including scenario analysis module, spatial analysis module, the conversion rules module and spatial analysis modules. Scenario analysis module is used to express the changed needs of a variety of land use types under different scenarios. Spatial analysis module is used to calculate the probability values of various land use types in each grid unit through spatial regression analysis for driving factors. Transfer rules module is used to express possibility and ease of a certain type of land transfer to another type of land on each grid cell. Space allocation module implements spatial distribution pattern of various land use types under different scenarios on the grid.

There are mainly four steps to carry out dynamic simulation of land use based on DLS. First, analyze statistical relationship between land use types distribution and driving factors from the two scales of region and grid, measure 


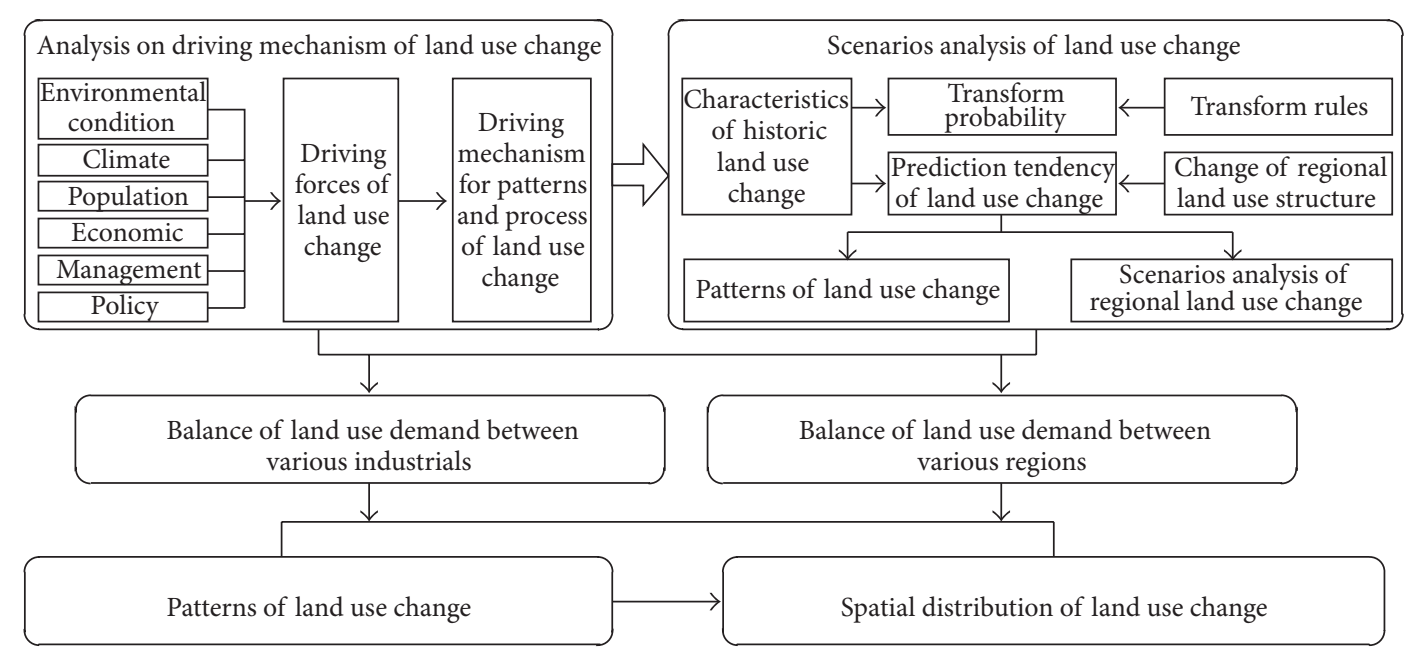

FIGURE 2: Framework of DLS model.

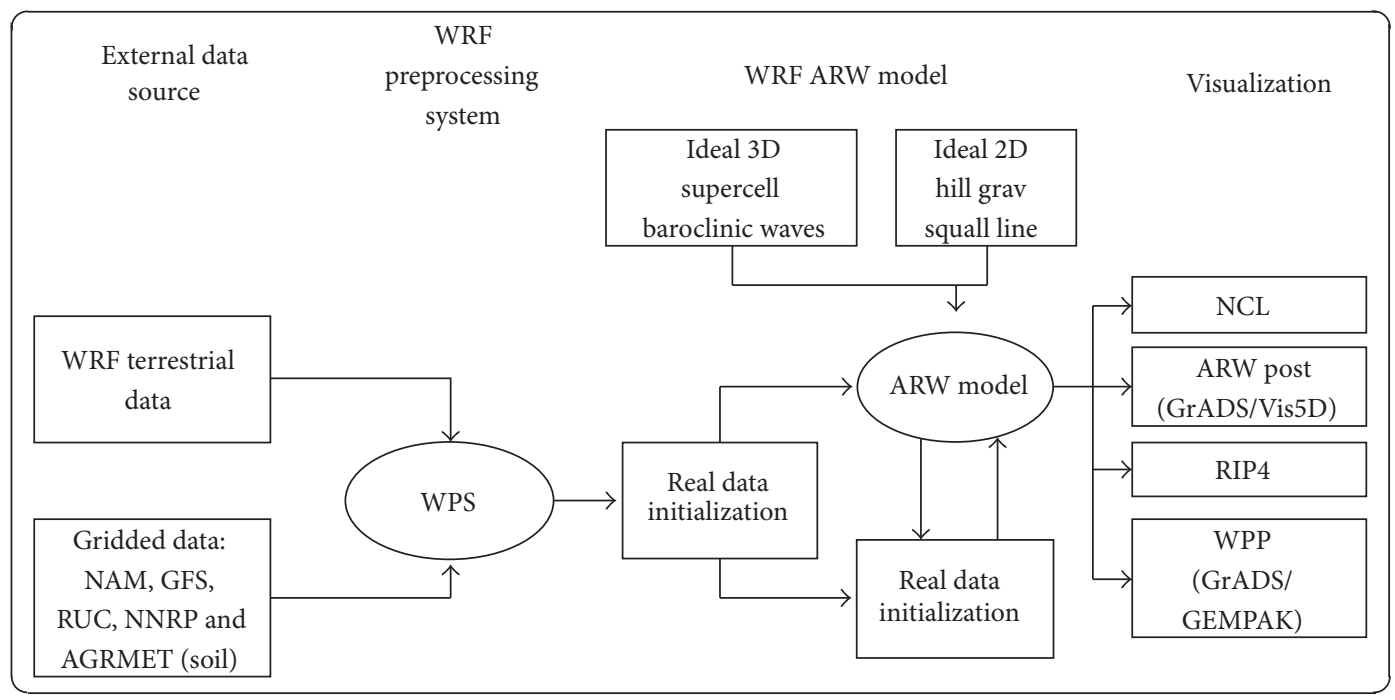

FIGURE 3: Framework of WRF model.

effects of the natural environment and socioeconomic factors on temporal patterns of regional land use, and extract the key factors which affect land use types distribution. Then, based on the history of land use characteristics and the status of regional land use changes, predict trends that the key factors influence land use patterns, and then select a reasonable scenario. According to supply-demand situation of different industries on land under this scenario during the time cross-section of forecast period, allocate area demand of different land types to various industries. Finally, by balance analysis of grid-scale land type area's demand and supply, achieve spatial distribution of different kinds of land use types on the grid scale and generate spatial pattern of land use.

According to the estimated result of the experiential model, the contribution on land use change of various independent variables can be calculated. Based on this, prediction of land use in 2010 and 2050 in Southern-Jiangsu can be worked out. Under the linear hypothesis, land use change process can be presented as the following formula:

$$
\Delta Y_{i}=f\left(\ldots, x_{i}^{t}, \ldots\right)-f\left(\ldots, x_{i}^{t-1}, \ldots\right)=f\left(\Delta x_{i}\right),
$$

where $\Delta Y_{i}$ is the change area of land use $Y_{i}, x_{i}^{t}$ and $x_{i}^{t-1}$ are the value of independent variables in time $t$ and $t-1$, respectively, and $\Delta x$ is the changed value of independent variables.

3.3. WRF Model. WRF model is a new generation mesoscale weather forecasting model and assimilation model which was jointly initiated by research institutes and scientists of universities in the United States [37]. This model is highly modular and layer-designed, the main program adds a number of optimization options in compiler, and the input and the output data are read in a variety of standard formats.

WRF model consists of three parts, including preprocessing module of mode (WPS), main module of model (ARW), 


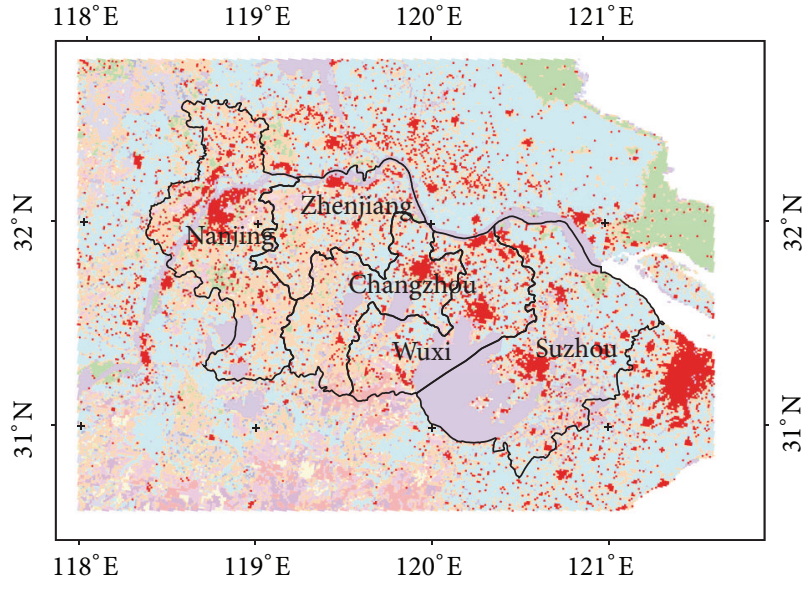

(a)

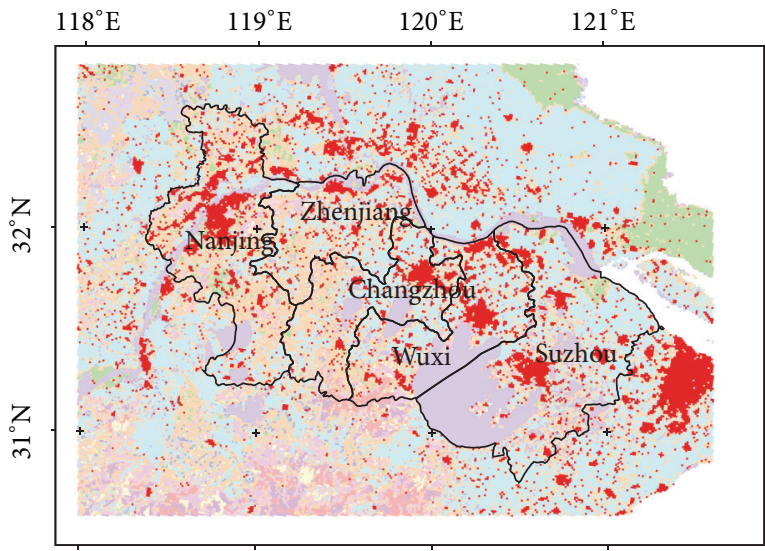

$118^{\circ} \mathrm{E}$ $119^{\circ} \mathrm{E}$ $120^{\circ} \mathrm{E}$

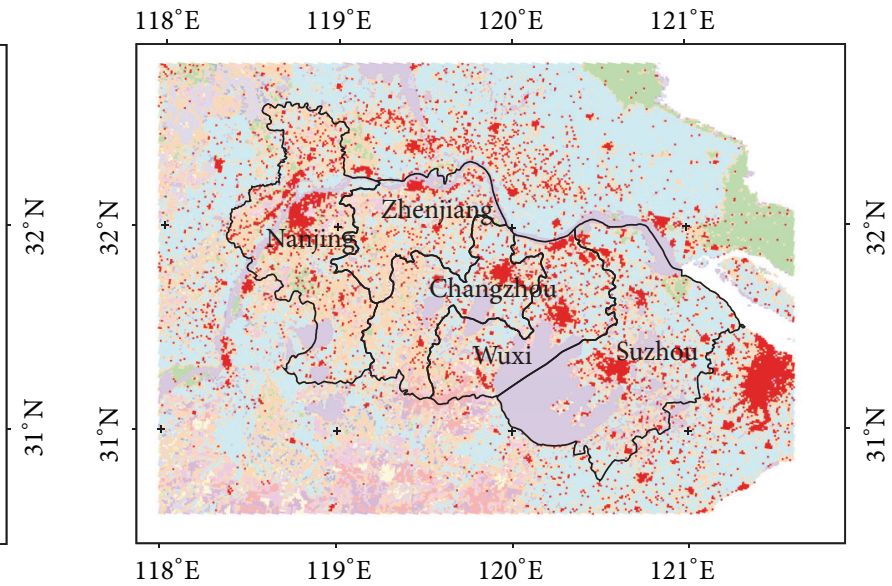

(b)

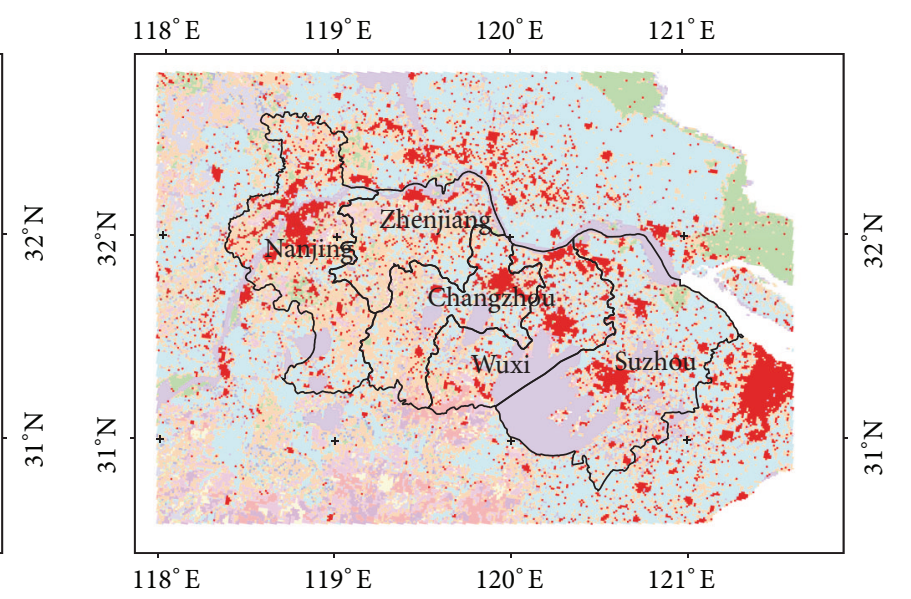

$118^{\circ} \mathrm{E}$

Urban and built-up land Dryland cropland and pasture Irrigated cropland and pasture

Mixed dryland/irrigated cropland and pasture Cropland/grassland mosaic

Cropland/woodland mosaic

Grassland

Shrubland

Mixed shrubland/grassland

Deciduous broadleaf forest

Evergreen broadleaf forest

Evergreen needleleaf forest

Mixed forest

Water bodies

FIGURE 4: Results of land use change simulation. (a) and (b) show the simulation results of land use in Southern-Jiangsu in year 2010 under REG scenario and CES scenario, respectively; (c) and (d) show the simulation results of land use in Southern-Jiangsu in year 2050 under REG scenario and CES scenario, respectively.

and assimilation module of mode and postprocessing tools of mode data (WRF-VAR) (Figure 3). Preprocessing module of the model mainly determines the analog areas, providing initial and boundary conditions of simulation, providing topography and soil types data and entrusting to the grid area of simulation, reentrusting the meteorological data to grid of simulation. ARW is the core part of the model and mainly makes initialization and integration for simulation.

WRF model is mainly applied to the weather and climate research when horizontal resolution is $1-10 \mathrm{~km}$. It can also be applied to numerical simulation, physical parameterizations research, data assimilation, and numerical ideal test and 
provide meteorological field for air quality model. This paper simulated the future land use change in Southern-Jiangsu using the DLS model and made dynamic simulations to regional climate change under different underlying scenarios based on the WRF model, just to reveal the impacts of Southern-Jiangsu's future land use change on regional climate change.

\section{Results}

4.1. Scenario Analysis of Future Land Use in SouthernJiangsu. Future land use conditions in Southern-Jiangsu are simulated under two kinds of scenarios in this paper. After 30 years' development under the reform and opening up policy in China, the Southern-Jiangsu has achieved rapid socioeconomic progress. Meanwhile, the Southern-Jiangsu's resources and environment are also under tremendous pressure. Particularly, farmland resources in this area are facing significant stress of reduction under the circumstance of rapid urban expansion. Southern-Jiangsu's resources and environmental pressures have become increasingly prominent in the process of rapid economic development. Therefore, the development of Southern-Jiangsu is facing new opportunities and challenges. Against this background, this paper set Southern-Jiangsu's future land use scenarios as REG scenario and CES scenario. The core of REG scenario is that land use demands have the priority in land use change. Southern-Jiangsu's land use change has served the purpose of economic development in the past 30 years; therefore, it can be considered that Southern-Jiangsu's land use scenario was the REG scenario in the past 30 years. The core of CES scenario is to achieve coordination between economic development and environmental protection. Therefore, the purpose of the land use in CES scenario is to realize the transformation of economic development so as to protect natural resources and environment by sacrificing the speed of economic development rationally.

This study simulated the land use change in SouthernJiangsu during 2010 to 2050 under the REG scenario and CES scenario with the DLS model (Figure 4). The result under the REG scenario suggests that the built-up land expansion in 2010 mainly concentrated on the main urban areas of Nanjing, Zhenjiang, Suzhou, Wuxi, and Changzhou, which is consistent with the trend of the current land use change in Southern-Jiangsu. While the simulation result under the CES scenario indicates that the built-up land will expand dispersedly in the whole study area, the built-up land expansion around the main urban areas of Nanjing, Zhenjiang, Suzhou, Wuxi, and Changzhou will be restrained to some degree.

The simulation result in year 2050 indicates that there is still a great demand of economic development for the land resource under the REG scenario since the REG will keep a high speed in Southern-Jiangsu. The built-up land will expand most obviously around the main urban areas of Nanjing, Zhenjiang, Suzhou, Wuxi, and Changzhou, where the area of cultivated land and forests will further decrease. There will also be some expansion of the built-up land

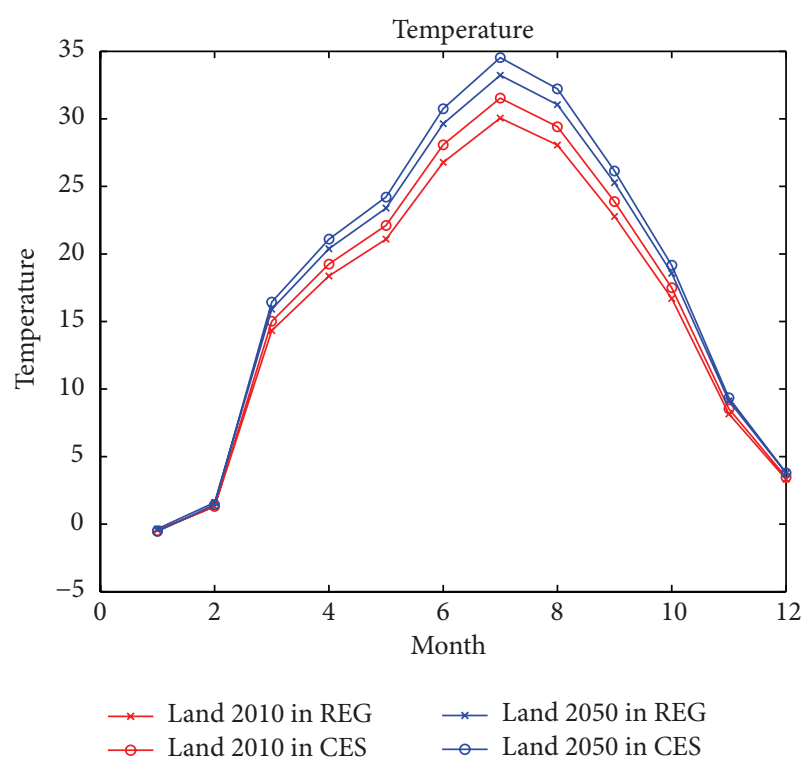

FIGURE 5: Simulated monthly average temperature in SouthernJiangsu under different scenarios (unit: ${ }^{\circ} \mathrm{C}$ ). Land 2010 in REG scenario and Land 2010 in CES scenario represent the monthly average temperature simulated with the LUCC data in 2010 under the REG scenario and CES scenario as the underlying data, respectively. Land 2050 in REG scenario and Land 2050 in CES scenario refer to that in 2050 .

in the small-medium cities, which puts great pressure on the surrounding cultivated land and forests. Under the CES scenarios, the speed of economic development will be restrained to some degree, and the land use intensity will be further improved and the consumption of land resources due to economic development will also be restrained. Although there will still be some expansion of built-up land around the main urban areas of Nanjing, Zhenjiang, Suzhou, Wuxi, and Changzhou, the expansion degree is much limited compared to that under the REG scenario. The area of cultivated land and forests will decrease slightly due to the built-up land expansion, but the decreased area has been under control compared to that under the REG scenarios, in particular, the shrinkage of forests is well controlled in these regions. By comparison, the built-up land in small-medium cities still expands dispersedly, but the expansion speed is obviously restrained.

4.2. Impacts of the Future Land Use Change on the Regional Temperature in Southern-Jiangsu. Based on the simulation results of the future land use change in Southern-Jiangsu, the WRF was used to simulate the impacts of the land use change on the regional climate change in the future under different scenarios. The underlying surface data were first generated through up-scaling and reclassifying the simulation results of land use change in Southern-Jiangsu according to the requirement of the WRF model. Then the static underlying surface data in the WRF model were replaced with the dynamic ones in 2010 and 2050 under the REG scenario and CES scenario; thereafter the future regional climate change 


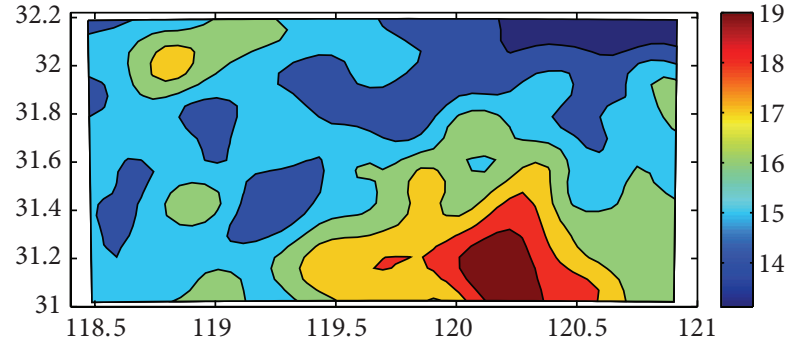

(a)

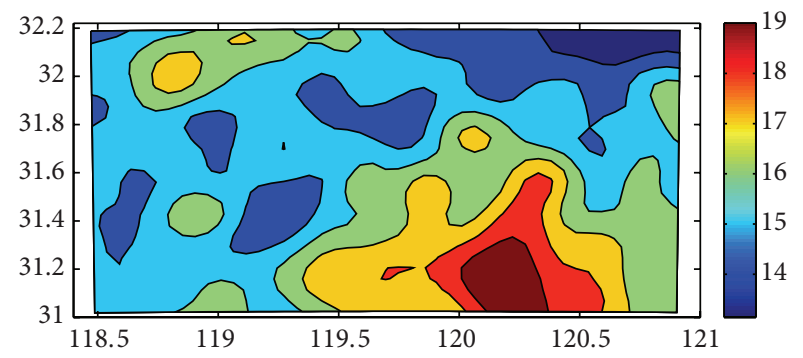

(c)

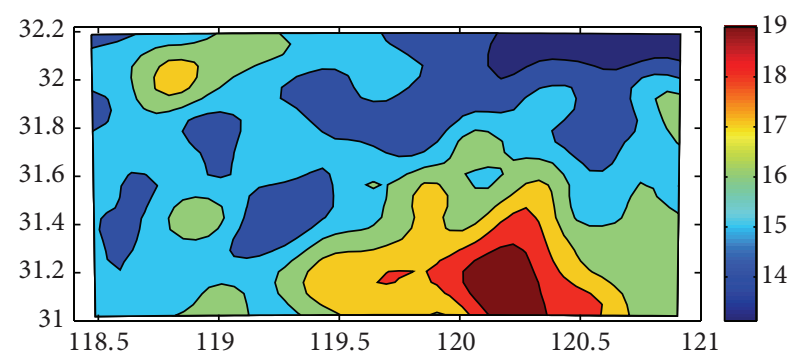

(b)

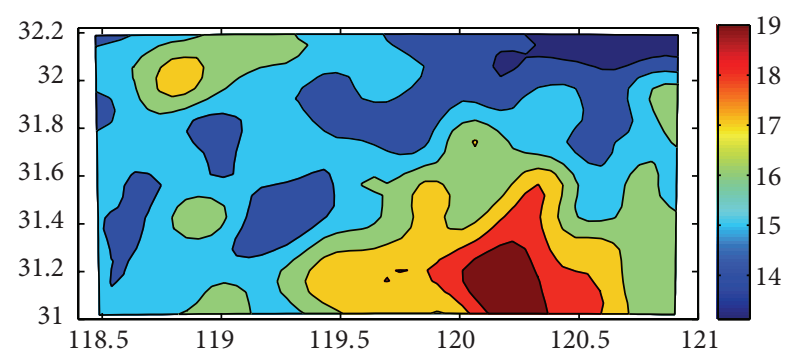

(d)

Figure 6: Spatial pattern of the monthly average temperature in Southern-Jiangsu under different scenarios (unit: ${ }^{\circ} \mathrm{C}$ ). (a) and (b) show the simulation result of average temperature of land use in Southern-Jiangsu in year 2010 under REG scenario and CES scenario, respectively; (c) and (d) show the simulation result of average temperature of land use in Southern-Jiangsu in year 2050 under REG scenario and CES scenario, respectively.

was simulated and finally the climate effects of different underlying surfaces were analyzed (Figure 5).

The simulation results indicate that the changing trends of the monthly average temperatures under different scenarios are consistent on the whole. The highest monthly average temperatures all appear in June, July, and August, and the lowest ones all appear in November, January, and February. This result shows that the changes of underlying surface do not affect the monthly temperature change trend; it only affects the value of average temperature. There is significant difference on the monthly average temperatures during different periods under different scenarios. The simulation results indicate that the regional monthly average temperature in 2010 under the CES scenario is the lowest on the whole, while that in 2050 under the REG scenario is the highest. Besides, the monthly average temperature in 2010 under the REG scenario is slightly higher than in 2050 under the CES scenario. In addition, there are also some differences in the monthly average temperatures between different underlying surfaces during different periods. Overall, the greatest difference in the monthly average temperatures appears in summer, while there is no significant difference in winter, with that in January being the slightest.

The simulation result indicates that there are significant impacts of the underlying surface on the spatial pattern of the monthly average temperature under different scenarios, especially in 2050 under the REG scenario and in 2010 under the CES scenario (Figure 6). Figures 6(a) and 6(b) suggest that there is no significant difference between the spatial pattern of the monthly average temperature on the underlying surfaces under the REG scenario and the CES scenario in 2010, and the monthly average temperature under the REG scenario is only slightly higher than that under the REG scenario. However, Figures 6(c) and 6(d) indicate that the regions with high temperature in 2050 under the REG scenario are much wider than the high temperature regions under the CES scenario, especially around the center of big cities such as Nanjing, Zhenjiang, Suzhou, and Wuxi. According to the comparison of results between the monthly average temperature in 2050 under the REG scenario and other scenarios, the range of the high-temperature regions is much wider in 2050 under the REG scenario than other scenarios.

The biggest difference in the monthly average temperature under different scenarios is in July; therefore, the impacts of different underlying surfaces on the temperature can be more clearly revealed through comparing the spatial pattern of the monthly average temperature in July (Figure 7). Figure 7 shows that the impacts of different underlying surfaces on the spatial pattern of the temperature in SouthernJiangsu in July are consistent with its spatial pattern on the monthly average temperature, but the scope of high temperature is more significant in July. Taking the results in 2050 under the REG scenario and CES scenario (Figures $7(\mathrm{c})$ and $7(\mathrm{~d})$ ) as examples, the high-temperature region in Nanjing has expanded into a separate continuous region in 2050 under the CES scenario, while the scope of the high-temperature region in Zhenjiang is still very limited. Besides, the high-temperature regions in Suzhou, Wuxi, and Changzhou have also expanded into a large continuous district, but its scope and temperature range are both smaller than the scope and temperature range in 2050 under the REG scenario. 


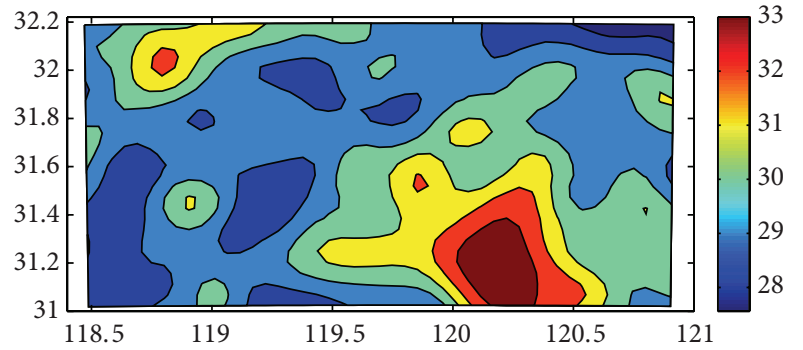

(a)

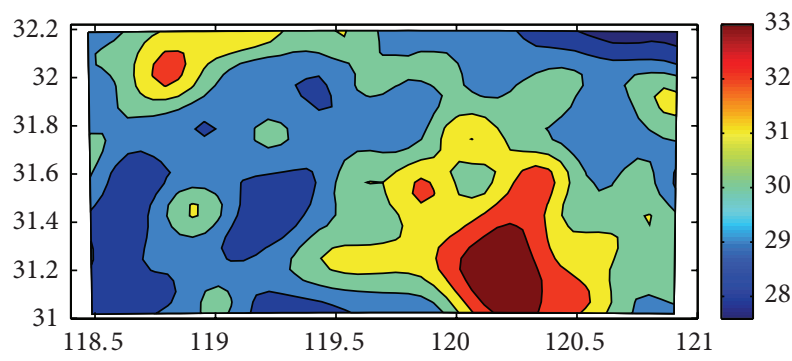

(c)

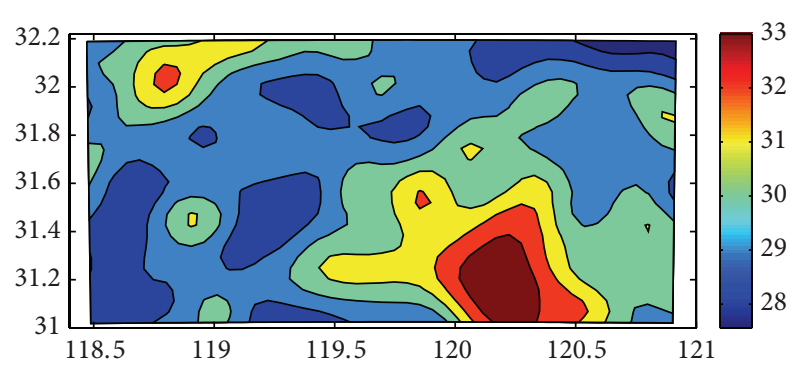

(b)

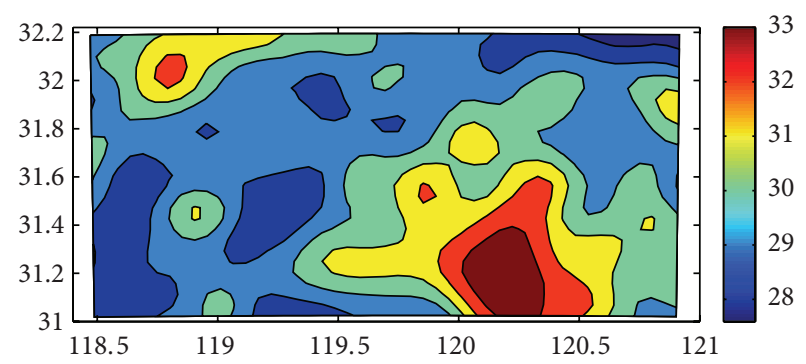

(d)

FIGURE 7: Spatial pattern of the monthly average temperature in Southern-Jiangsu in July under different scenarios (unit: $\left.{ }^{\circ} \mathrm{C}\right) .(\mathrm{a})$ and (b) show the simulation result of monthly average temperature in Southern-Jiangsu in July of land use in year 2010 under REG scenario and CES scenario, respectively; (c) and (d) show the simulation result of monthly average temperature in Southern-Jiangsu in July of land use in year 2050 under REG scenario and CES scenario, respectively.

4.3. Key Impact Mechanisms of the Future Land Use Change on the Regional Temperature in Southern-Jiangsu. According to the surface energy budget equation, there is close relationship between the surface net radiation, land surface albedo, downward shortwave radiation, downward long-wave radiation, and land surface emissivity:

$$
R_{n}=R_{n}^{S}+R_{n}^{l}=(1-\alpha) F_{d}^{s}+\varepsilon F_{d}^{l}-\sigma \varepsilon T^{4},
$$

where $R_{n}$ is the surface net radiation, $R_{n}^{S}$ is the short wave radiation, $R_{n}^{l}$ is the long-wave radiation, $\alpha$ is the land surface albedo, $F_{d}^{S}$ is the downward shortwave radiation, $\varepsilon$ is the land surface emissivity, $F_{d}^{l}$ is the downward long-wave radiation, and $T$ is the land surface temperature. The land net radiation is the energy source of the land surface temperature change, this study has focused on how the underlying surface change influences the land surface albedo, downward shortwave radiation, downward long-wave radiation, and land surface emissivity in order to clarify the key influencing mechanism of the future land use change on the regional temperature in Southern-Jiangsu (Figure 8).

The land use change in Southern-Jiangsu mainly influences the land net radiation through exerting impacts on the land surface albedo and emissivity, and the land use change influences the spatial heterogeneity of the land surface emissivity most greatly under both the scenarios (Figure 8). Figure 8(a) suggests that the land surface albedo will be the lowest in 2050 under the REG scenario, while it will show no significant difference under other scenarios. Besides, Figure 8(b) suggests that the land surface emissivity will be obviously lower in 2050 under the REG scenario than other scenarios, under which it will show no significant difference. In addition, Figures 8(c) and 8(d) indicate that there will not be significant difference in the downward long-wave radiation and downward shortwave radiation under all the scenarios. In summary, under the condition that there is no significant difference between the downward long-wave radiation and downward shortwave radiation, there will be lower land surface albedo and emissivity in 2050 under the REG scenario, which consequently greatly increases the land surface net radiation and thus lays foundation for the warming effects.

This study analyzed the impacts of the spatial heterogeneity of the land surface emissivity on the spatial pattern of temperature in the hottest month (July) since the difference in the land surface emissivity is the main reason for the warming effects in 2050 under the REG scenario (Figure 9).

Figure 9 shows that the regions with the lower land surface emissivity is more widespread in 2050 under the REG scenario than under other three scenarios. Under all the four scenarios, there are always continuous districts with lower land surface emissivity in Nanjing, Zhenjiang, Suzhou, Wuxi, and Changzhou, where the urban land is the main part of the underlying surface. However, the result clearly shows that the land surface emissivity in these continuous districts is obviously lower in 2050 under the REG scenario than other scenarios, which may be mainly because the underlying surface will change more greatly in 2050 under the REG scenario.

What is more, the land surface energy budget equation suggests that under the condition of certain land surface net radiation, the underlying surface mainly influences the 

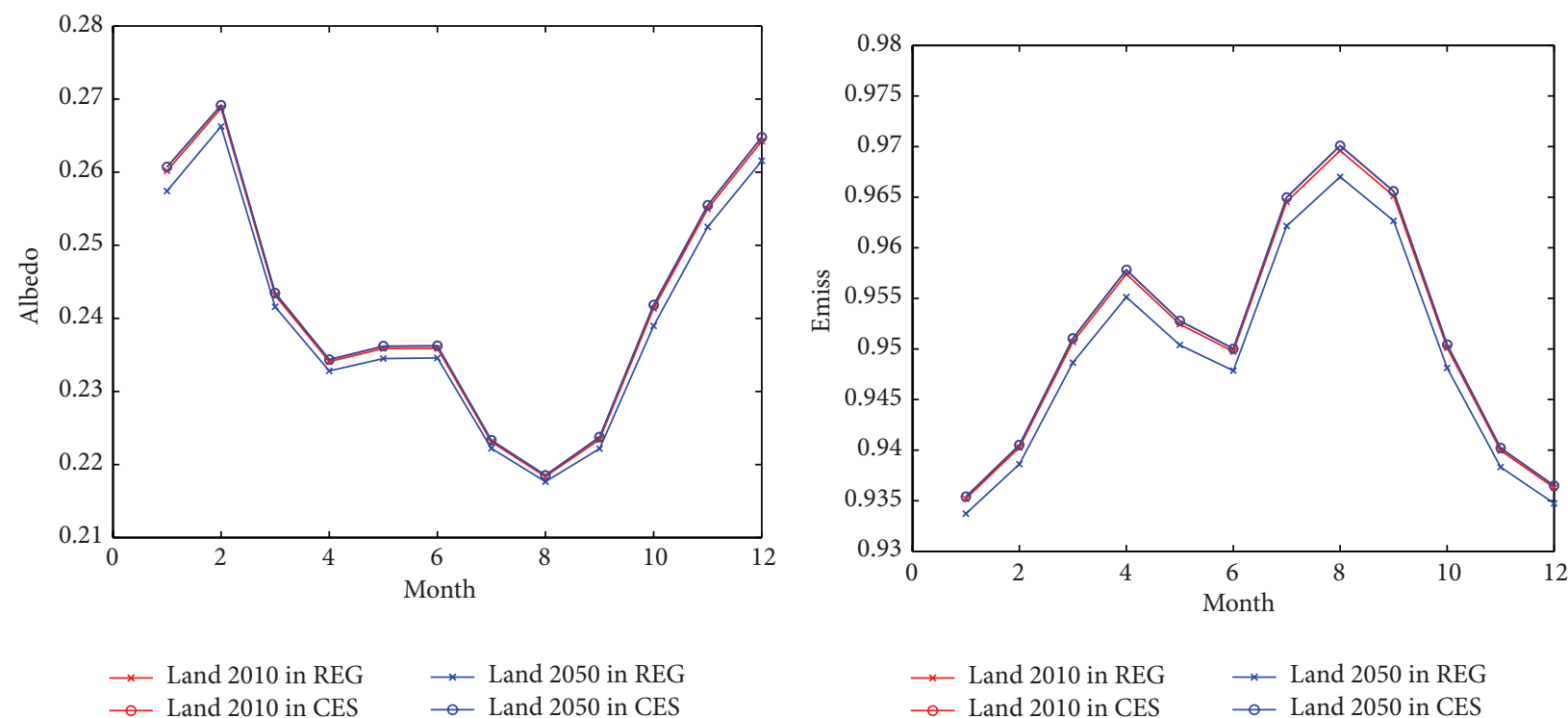

(a)

(b)
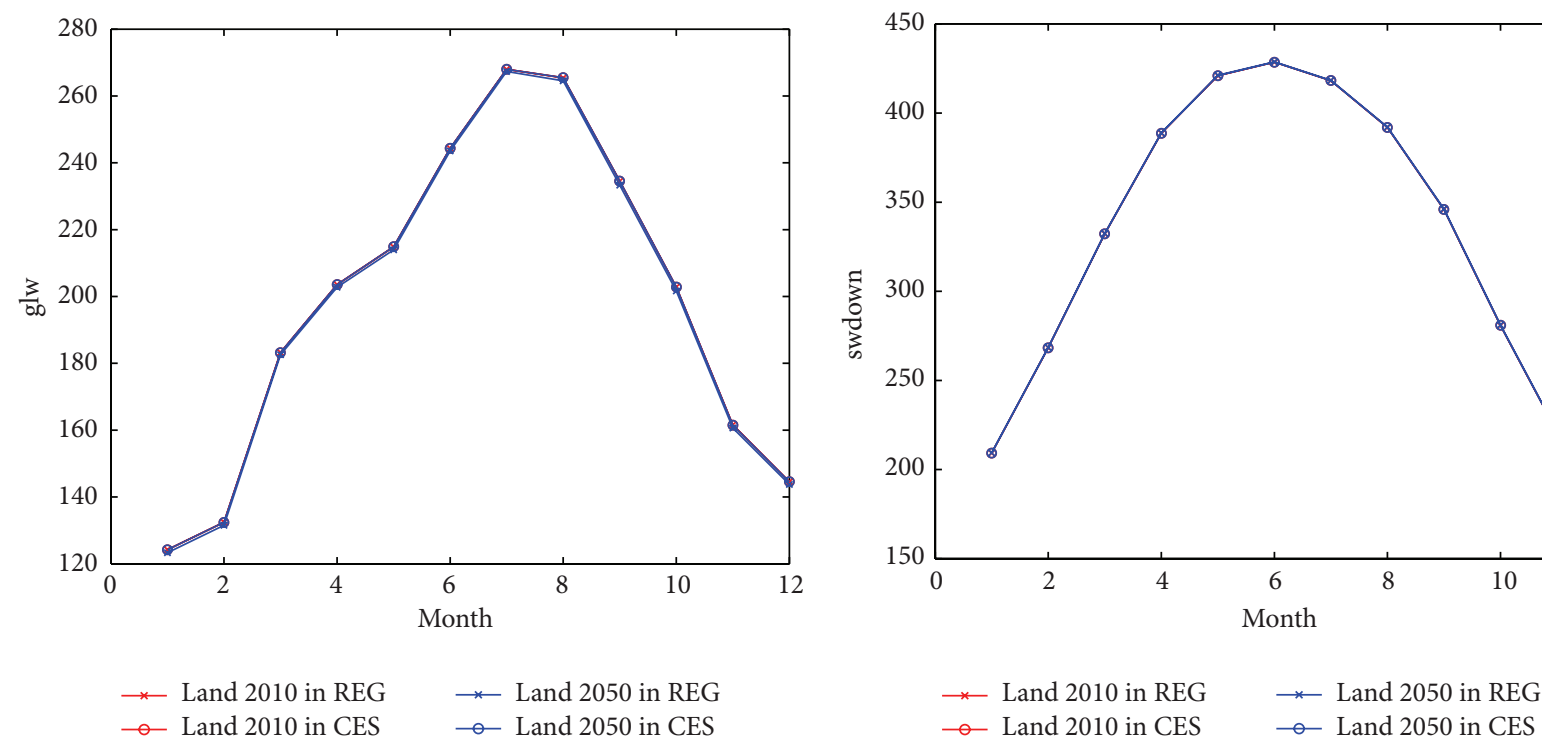

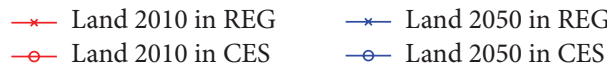

(c)

(d)

FIGURE 8: Influence of the future land use change on the key biogeophysical parameters in Southern-Jiangsu. (a) and (b) show the influence of the future land use change on albedo and surface emissivity; (c) and (d) show the influence of the future land use change on downward long-wave radiation and downward shortwave radiation $\left(\mathrm{W} / \mathrm{m}^{2}\right)$.

temperature through influencing the sensible heat flux, latent heat flux, and soil heat flux:

$$
R_{n}=H+\mathrm{LE}+G \text {, }
$$

where $R_{n}$ is the land surface net radiation, $H$ is the sensible heat flux, LE is the latent heat flux, and $G$ is the soil heat flux.

Since there is generally very limited heat flux into the soil layer, the land surface net radiation is mainly influenced by the sensible heat flux and latent heat flux, while the underlying surface can directly influence the latent heat flux and consequently influence the near-surface temperature.
Figure 10 shows that the latent heat flux is obviously lower in 2050 under the REG scenario than under other scenarios, and therefore the decrease of the latent heat flux caused by the underlying surface change due to land use change can be seen as one of the main causes of the temperature rise in SouthernJiangsu.

In order to further analyze the impacts of the difference in the latent heat flux on the spatial pattern of temperature, the spatial pattern of the latent heat flux under different scenarios were further analyzed (Figure 11). It can be seen that there is no significant difference in the spatial pattern of the latent heat flux in Southern-Jiangsu under different scenarios. 


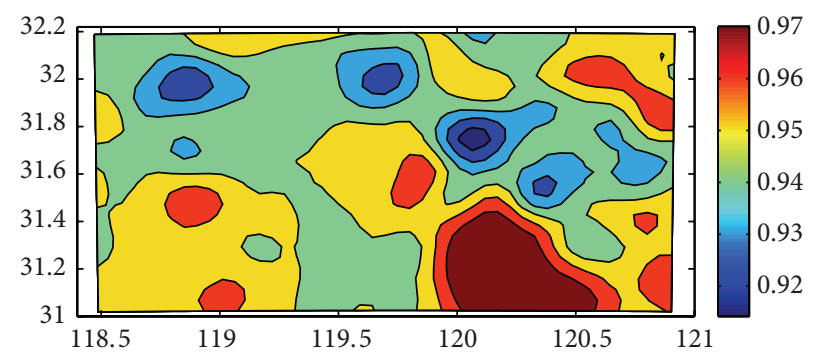

(a)

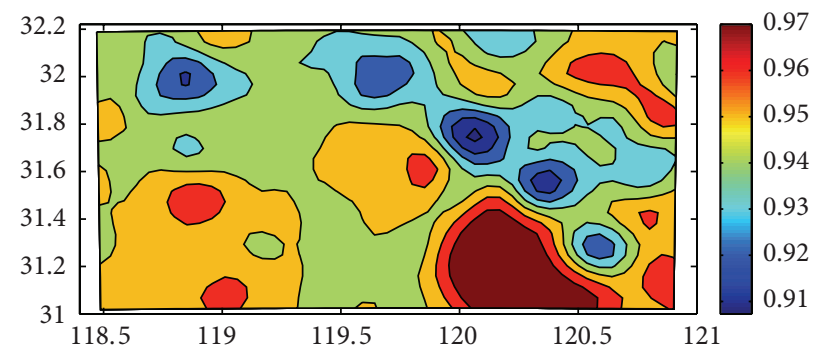

(c)

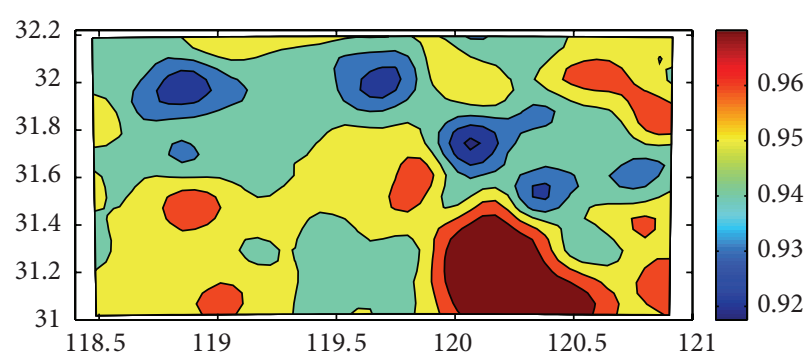

(b)

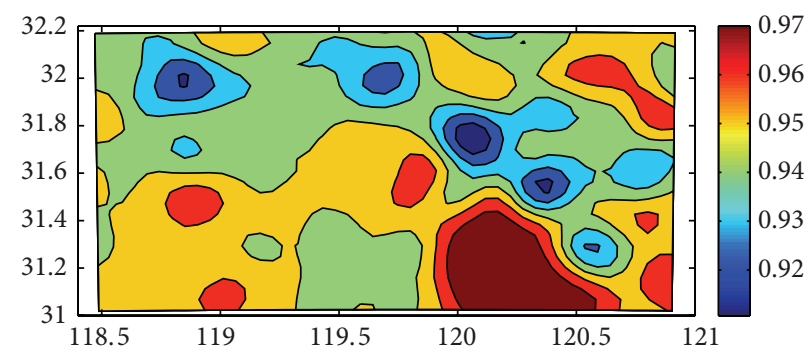

(d)

FIGURE 9: Spatial pattern of the land surface emissivity in Southern-Jiangsu under different scenarios. (a) and (b) show the simulation result of land surface emissivity of land use in Southern-Jiangsu in year 2010 under REG scenario and CES scenario, respectively; (c) and (d) show the simulation result of land surface emissivity of land use in Southern-Jiangsu in year 2050 under REG scenario and CES scenario, respectively.

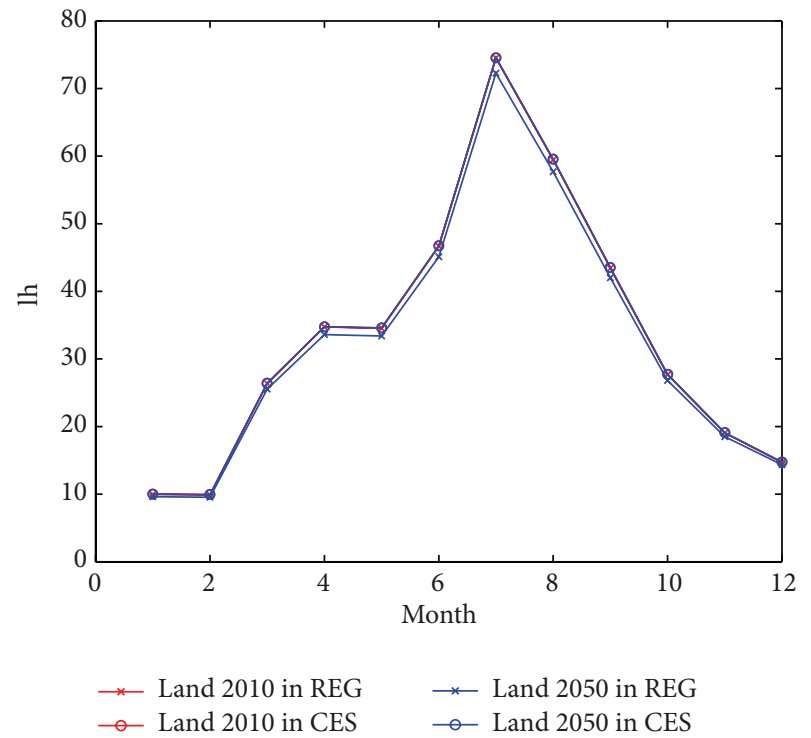

FIGURE 10: Comparison of the latent heat flux in Southern-Jiangsu under different scenarios (unit: $\mathrm{W} / \mathrm{m}^{2}$ ).

However, the variation range of the latent heat flux in 2050 is smaller under the REG scenario than under other scenarios.

\section{Discussion and Conclusion}

The scientific understanding of the impacts of land use change on the regional climate change provides the foundation for reasonable land use management so as to mitigate the climate change. Taking Southern-Jiangsu, the typical region of urbanization in China, as the study area, this study analyzed the influence of land use change on the temperature under the REG scenario and CES scenario during 2010-2050 on the basis of simulation with the DLS model and WRF model. This study then analyzed the impacts of land use change on the key biogeophysical parameters such as surface net radiation, land surface albedo, downward shortwave radiation, downward long-wave radiation, and land surface emissivity from the perspective of land surface radiation budget and energy balance. Furthermore, the key influencing mechanisms of the future land use change on the regional temperature was analyzed. The main conclusions are as follows.

(1) The land use change in Southern-Jiangsu shows different changing trends under different scenarios, but it is mainly characterized by the expansion of urban land and shrinkage of the cultivated land and forests. Under the REG scenario, the urban land expansion in Southern-Jiangsu will keep at a fast rate; the urban land will mainly expand around the central cities, mainly occupying the cultivated land and forests. By contrast, the built-up land will expand dispersedly in the whole study area under the CES scenario, and the builtup land expansion around the main cities will be restricted to some degree.

(2) The monthly average temperature in SouthernJiangsu shows a consistent changing trend under different scenarios, but the temperature range shows significant difference. The highest value of the monthly average temperature appears in July under all the scenarios, while the lowest one appears in January. Besides, the regional monthly average temperature is the highest in 2050 under the REG scenario 


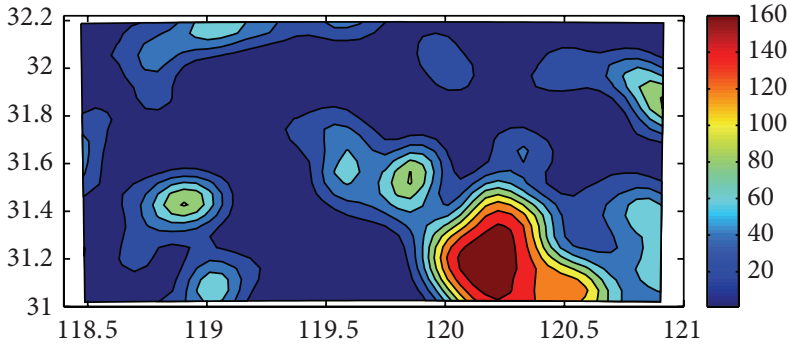

(a)

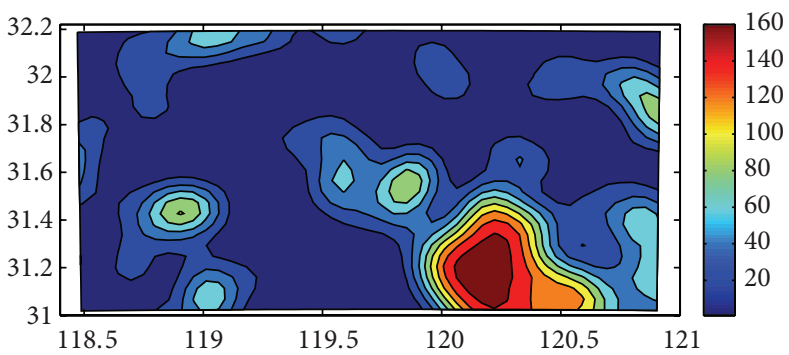

(c)

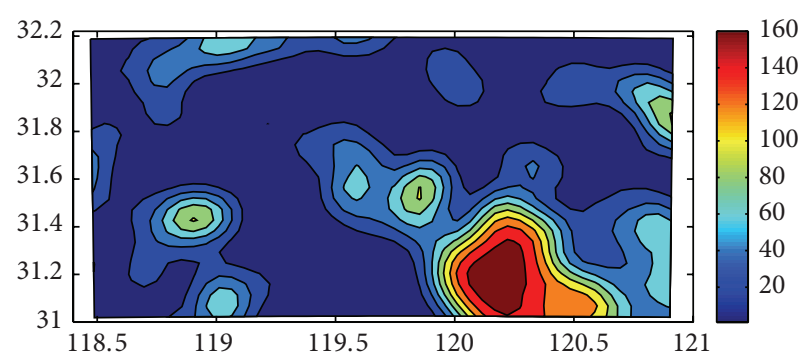

(b)

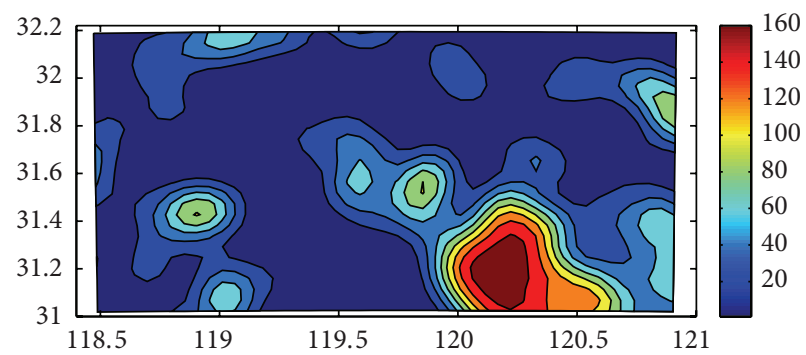

(d)

FIGURE 11: Spatial pattern of the latent heat flux in Southern-Jiangsu under different scenarios (unit: mm). (a) and (b) show the simulation result of latent heat flux of land use in Southern-Jiangsu in year 2010 under REG scenario and CES scenario, respectively; (c) and (d) show the simulation result of latent heat flux of land use in Southern-Jiangsu in year 2050 under REG scenario and CES scenario, respectively.

and the lowest in 2010 under the CES scenario. In addition, the difference in the monthly average temperatures is the greatest in the summer and the smallest in the winter.

(3) There is significant influence of the underlying surface on the spatial pattern of temperature. The spatial pattern differs most greatly in 2050 under the REG scenario and in 2010 under the conservation scenario, especially in July. The range of the high-temperature regions is much wider in 2050 under the REG scenario than it is in 2010 under the CES scenario. The high-temperature regions are much wider in 2050 under the REG scenario than it is under the CES scenario, especially in big cities such as Nanjing, Zhenjiang, Suzhou, and Wuxi.

(4) The land use change in Southern-Jiangsu mainly influences the regional temperature through altering the land surface net radiation and latent heat flux. The land surface net radiation, which depends on the land surface albedo and emissivity, downward long-wave radiation, and downward shortwave radiation, plays a dominant role in influencing the temperature. Meanwhile, there is no significant influence of the land use change on the spatial pattern of the latent heat flux. In addition, the land surface albedo and emissivity play the most important roles in influencing the land surface net radiation, and there is no significant influence of the underlying surface on the downward long-wave radiation and downward shortwave radiation.

This study analyzed the influence of the future land use change (especially the urban land expansion) on the regional temperature in Southern-Jiangsu; it further analyzed the impacts of land use change on the key biogeophysical parameters from the perspective of land surface radiation budget and energy balance. The result of this study is of great significance to guide land management practices to mitigate the regional climate change. The precipitation as another important aspect of the regional climate change has not been considered since this study mainly focused on the influencing mechanism of the land use change on the regional temperature in rapidly urbanizing regions. Therefore, it is still necessary to carry out more in-depth research on the influence of the land use change on the regional climate change.

\section{Conflict of Interests}

The authors declare that there is no conflict of interests regarding to the publication of this paper.

\section{Acknowledgments}

This research was financially supported by the National Key Programme for Developing Basic Science of China (Grant no. 2010CB950900), the National Natural Science Foundation of China (Grant no. 41101098), the Ministry of Education Research of Social Sciences Youth funded Projects of China (Grant no. 10YJC790121), and the National Department Public Benefit Research Foundation of the Ministry of Land and Resources of China (Grant no. 201311001-5).

\section{References}

[1] Q. H. Weng, "Fractal analysis of satellite-detected urban heat island effect," Photogrammetric Engineering and Remote Sensing, vol. 69 , no. 5, pp. 555-566, 2003. 
[2] J. B. Basara, H. G. Basara, B. G. Illston, and K. C. Crawford, "The impact of the urban heat island during an intense heat wave in Oklahoma city," Advances in Meteorology, vol. 2010, Article ID 230365, 10 pages, 2010.

[3] E. F. Lambin and H. Geist, "Global land-use and land-cover change: what have we learned so far?" Global Change Newsletter, no. 46, pp. 27-30, 2001.

[4] R. A. Pielke Sr., J. Adegoke, A. Beltrán-Przekurat et al., "An overview of regional land-use and land-cover impacts on rainfall," Tellus B, vol. 59, no. 3, pp. 587-601, 2007.

[5] S. A. Changnon, "Inadvertent weather modification in urban areas: lessons for global climate change," Bulletin of the American Meteorological Society, vol. 73, no. 5, pp. 619-627, 1992.

[6] S. K. Jusuf, N. H. Wong, E. Hagen, R. Anggoro, and Y. Hong, "The influence of land use on the urban heat island in Singapore," Habitat International, vol. 31, no. 2, pp. 232-242, 2007.

[7] J. L. Weiss, D. S. Gutzler, J. E. Allred Coonrod, and C. N. Dahm, "Seasonal and inter-annual relationships between vegetation and climate in central New Mexico, USA," Journal of Arid Environments, vol. 57, no. 4, pp. 507-534, 2004.

[8] W. T. L. Chow, D. Brennan, and A. J. Brazel, "Urban heat island research in Phoenix, Arizona: theoretical contributions and policy applications," Bulletin of the American Meteorological Society, vol. 93, no. 4, pp. 517-530, 2012.

[9] L. Ka and N. Edward, "An investigation of urbanization effect on urban and rural Hong Kong using a 40-year extended temperature record," Landscape and Urban Planning, vol. 114, pp. 42-52, 2013.

[10] W. T. L. Chow and M. Roth, "Temporal dynamics of the urban heat island of Singapore," International Journal of Climatology, vol. 26, no. 15, pp. 2243-2260, 2006.

[11] I. D. Stewart, "A systematic review and scientific critique of methodology in modern urban heat island literature," International Journal of Climatology, vol. 31, no. 2, pp. 200-217, 2011.

[12] D. E. Parker, "Large-scale warming is not urban," Nature, vol. 432, no. 7015, p. 290, 2004.

[13] D. E. Parker, "A demonstration that large-scale warming is not urban," Journal of Climate, vol. 19, no. 12, pp. 2882-2895, 2006.

[14] Z. Guo, S. Wang, M. Cheng, and Y. Shu, "Assess the effect of different degrees of urbanization on land surface temperature using remote sensing images," Procedia Environmental Sciences, vol. 13, pp. 935-942, 2012.

[15] S. A. Changnon Jr., "Rainfall changes in summer caused by St. Louis," Science, vol. 205, no. 4404, pp. 402-404, 1979.

[16] R. E. Horton, “Thunderstorm-breeding spots," Monthly Weather Review, vol. 49, no. 4, p. 193, 1921.

[17] S. D. Chow and C. Chang, "Shanghai urban influences on humidity and precipitation distribution," GeoJournal, vol. 8, no. 2, pp. 201-204, 1984.

[18] R. C. Balling Jr. and S. W. Brazel, "Recent changes in Phoenix, Arizona summertime diurnal precipitation patterns," Theoretical and Applied Climatology, vol. 38, no. 1, pp. 50-54, 1987.

[19] E. Jauregui and E. Romales, "Urban effects on convective precipitation in Mexico city," Atmospheric Environment, vol. 30, no. 20, pp. 3383-3389, 1996.

[20] J.E. Diem and D. P. Brown, "Anthropogenic impacts on summer precipitation in central Arizona, USA," Professional Geographer, vol. 55, no. 3, pp. 343-355, 2003.

[21] J. M. Shepherd, H. Pierce, and A. J. Negri, "Rainfall modification by major urban areas: observations from spaceborne rain radar on the TRMM satellite," Journal of Applied Meteorology, vol. 41, no. 7, pp. 689-701, 2002.

[22] M. K. Kim and S. Kim, "Quantitative estimates of warming by urbanization in South Korea over the past 55 years (19542008)," Atmospheric Environment, vol. 45, no. 32, pp. 5778-5783, 2011.

[23] Q. Li, H. Zhang, X. Liu, and J. Huang, "Urban heat island effect on annual mean temperature during the last 50 years in China," Theoretical and Applied Climatology, vol. 79, no. 3-4, pp. 165-174, 2004.

[24] Q. Li, W. Li, P. Si et al., "Assessment of surface air warming in northeast China, with emphasis on the impacts of urbanization," Theoretical and Applied Climatology, vol. 99, no. 3-4, pp. 469-478, 2010.

[25] E. Kalnay and M. Cai, "Impact of urbanization and land-use change on climate," Nature, vol. 423, no. 6939, pp. 528-531, 2003.

[26] X. C. Yang, Y. L. Hou, and B. D. Chen, "Observed surface warming induced by urbanization in east China," Journal of Geophysical Research, vol. 116, no. 14, 2011.

[27] K. E. Trenberth, "Rural land-use change and climate," Nature, vol. 427, article 213, 2004.

[28] R. S. Vose, T. R. Karl, D. R. Easterling, C. N. Williams, and M. J. Menne, "Impact of land-use change on climate," Nature, vol. 427, no. 6971, pp. 213-214, 2004.

[29] T. L. Mote, M. C. Lacke, and J. M. Shepherd, "Radar signatures of the urban effect on precipitation distribution: a case study for Atlanta, Georgia," Geophysical Research Letters, vol. 34, no. 20, Article ID L20710, 2007.

[30] L. M. Hand and J. M. Shepherd, "An investigation of warmseason spatial rainfall variability in Oklahoma city: possible linkages to urbanization and prevailing wind," Journal of Applied Meteorology and Climatology, vol. 48, no. 2, pp. 251-269, 2009.

[31] C. Mitra, J. M. Shepherd, and T. Jordan, "On the relationship between the premonsoonal rainfall climatology and urban land cover dynamics in Kolkata city, India," International Journal of Climatology, vol. 32, no. 9, pp. 1443-1454, 2012.

[32] J. Thielen, W. Wobrock, A. Gadian, P. G. Mestayer, and J. D. Creutin, "The possible influence of urban surfaces on rainfall development: a sensitivity study in 2D in the meso- $\gamma$-scale," Atmospheric Research, vol. 54, no. 1, pp. 15-39, 2000.

[33] C. M. Rozoff and W. R. Cotton, "Simulation of St. Louis, Missouri, land use impacts on thunderstorms," Journal of Applied Meteorology, vol. 42, no. 6, pp. 716-738, 2003.

[34] W. Shem and M. Shepherd, "On the impact of urbanization on summertime thunderstorms in Atlanta: two numerical model case studies," Atmospheric Research, vol. 92, no. 2, pp. 172-189, 2009.

[35] L. Xie, J. Tang, Y. Lu, and X. Zhang, "A numerical simulation case of the effects of urbanization on regional extreme climatic events," Scientia Meteorologica Sinica, vol. 28, no. 1, pp. 74-80, 2008.

[36] J. Liu, Z. Zhang, X. U. Xinliang et al., "Spatial patterns and driving forces of land use change in China in the early 21st century," Acta Geographica Sinica, vol. 64, no. 12, pp. 1411-1420, 2009.

[37] W. C. Skamarock, J. B. Klemp, J. Dudhia et al., "A Description of the Advanced Research WRF Version 3," NCAR Technical Note NCAR/TN-475+STR, Mesoscale and Microscale Meteorology Division, National Center for Atmospheric Research, Boulder, Colo, USA, 2008. 

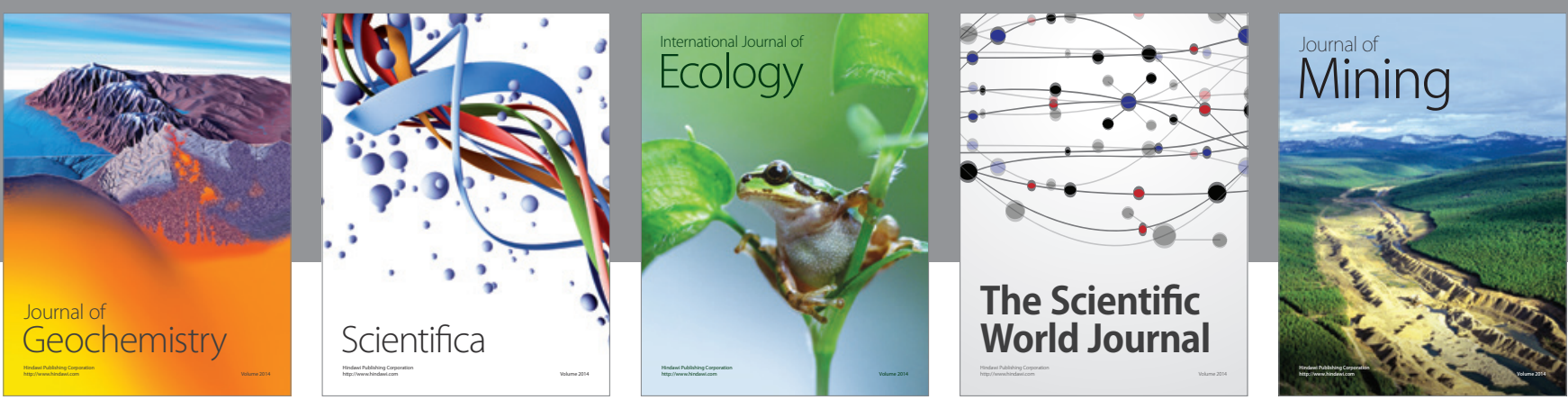

The Scientific World Journal
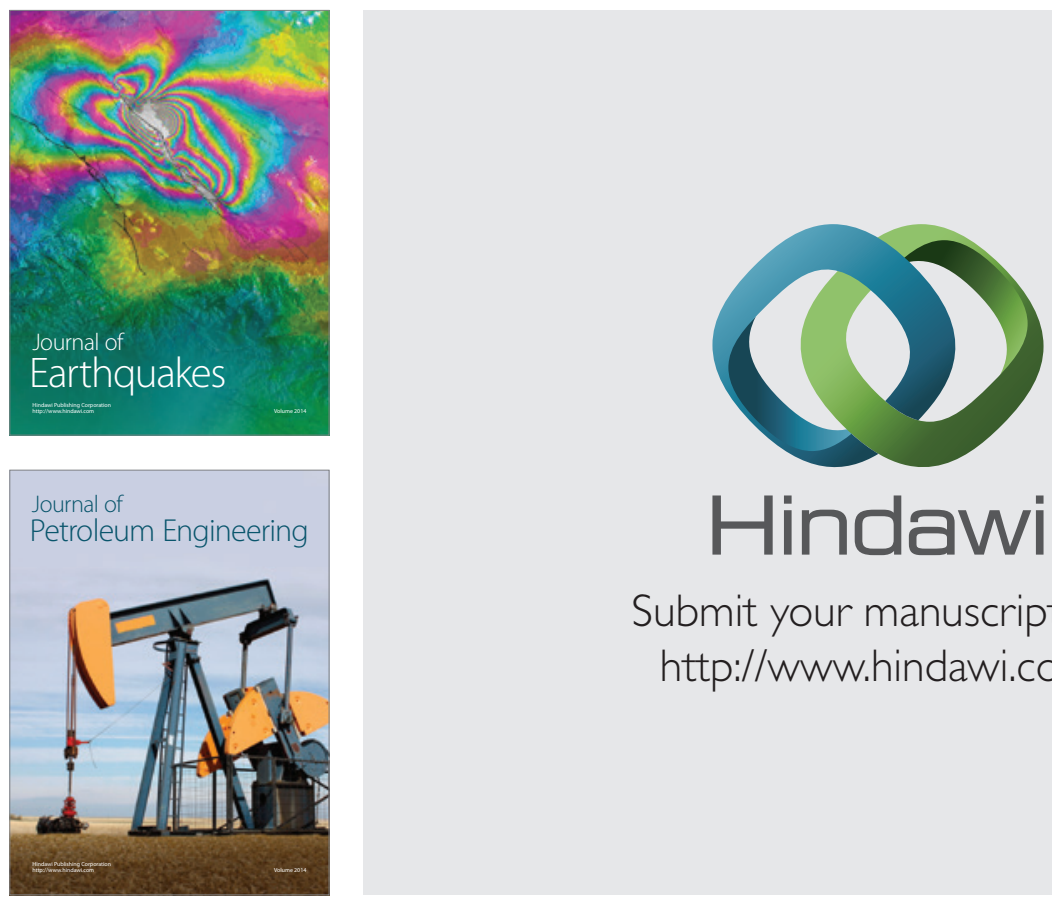

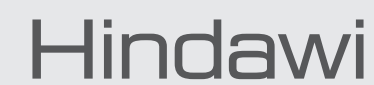

Submit your manuscripts at

http://www.hindawi.com
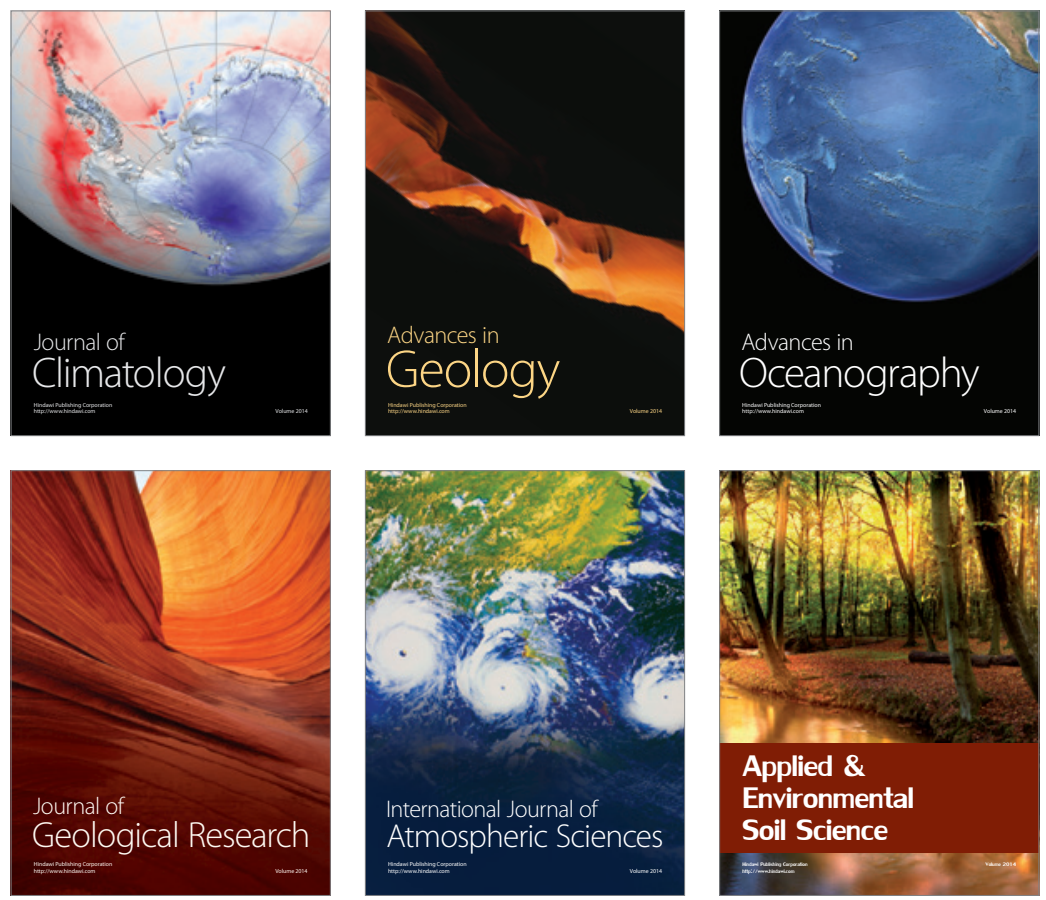
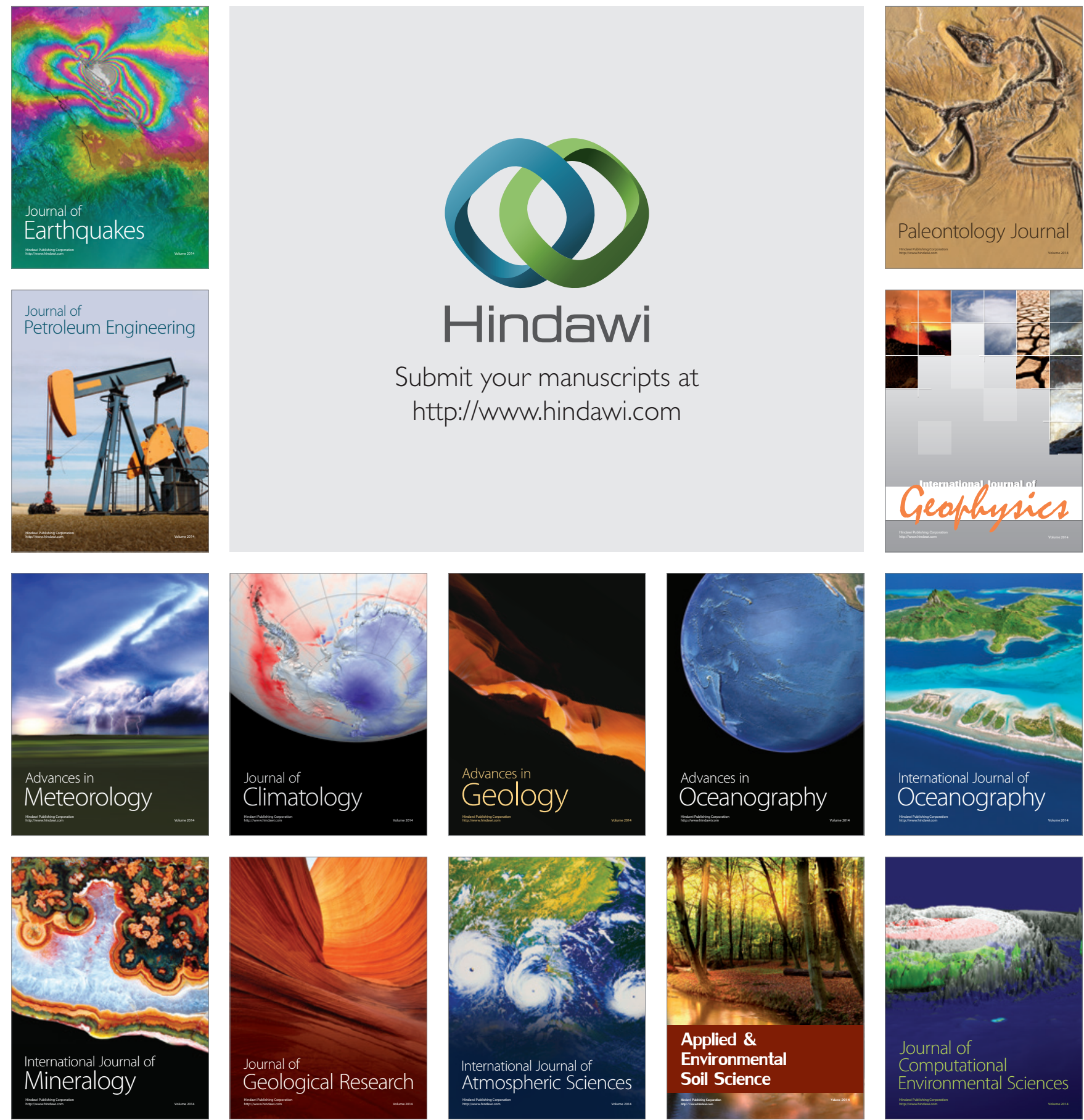